\title{
Inspiratory muscle strength and endurance during hyperinflation and histamine induced bronchoconstriction
}

\author{
RB Gorman, DK McKenzie, SC Gandevia, BL Plassman
}

Department of Respiratory Medicine D K McKenzie

Department of Clinical

Neurophysiology

Prince Henry and

Prince of Wales

Hospitals and Prince

of Wales Medical

Research Institute,

Faculty of Medicine,

University of New

South Wales, Sydney,

Australia

R B Gorman

S C Gandevia

B L Plassman

Reprint requests to:

Dr S C Gandevia, Prince of

Wales Medical Research

Institute, Prince Henry

Hospital, PO Box 233,

Matraville, NSW 2036,

Mydraville, Nustralia

Received 9 December 199

Returned to authors

21 February 1992

Revised version received

13 April 1992

Accepted 16 April 1992

\begin{abstract}
Background This study investigated whether the inspiratory muscles are susceptible to fatigue during acute airway narrowing because of increased airway resistance and hyperinflation.

Methods Asthmatic subjects performed up to four series (on separate days) of 18 maximal static inspiratory efforts of 10 seconds' duration with 10 second rest intervals $(50 \%$ duty cycle; total duration six minutes): at functional residual capacity (FRC) (control); after histamine induced bronchoconstriction, which decreased forced expiratory volume in one second $\left(F E V_{1}\right)$ to a mean of $55 \%$ (SD $11 \%$ ) of the initial value; at a voluntarily increased lung volume (initial volume held at $140 \%$ control); and after inhalation of histamine at a voluntarily increased lung volume.
\end{abstract}

Results For the group of subjects the mean (SD) maximal inspiratory pressure (MIP) in the control experiments was 114 (22) $\mathrm{cm} \mathrm{H}_{2} \mathrm{O}$ and the initial volume was 3.5 (1.2) 1. After histamine inhalation the initial lung volume for contractions increased to $118 \%(5 \%)$ of the control volume. In the high lung volume experiments initial volumes were $140 \%$ $(12 \%)$ of the control (volume without histamine) and $140 \%(15 \%)$ (with histamine). The relation between MIP and initial absolute lung volume was determined for each subject before fatigue developed. When the inspiratory pressures for each contraction in the endurance test were normalised to the pressure expected for that lung volume, no significant differences were found between the four experimental conditions for MIP, or between pressures sustained over the 18 contractions.

Conclusions Histamine induced bronchoconstriction and hyperinflation had no detectable effect on inspiratory muscle strength or endurance in these asthmatic subjects.

\section{(Thorax 1992;47:922-927)}

The hypothesis that the inspiratory muscles are especially prone to fatigue in acute asthma ${ }^{12}$ has never been tested directly. The increased resistive and elastic loads on breathing and the reduced reserve capacity to generate inspiratory pressures as a result of hyperinflation are likely to promote fatigue. Frequent loading of the inspiratory muscles may, however, act as a training stimulus for endurance. ${ }^{3}$ This has been documented in patients with poorly controlled asthma with daily symptomatic wheeze of more than 20 minutes' duration, but studied during remission. ${ }^{45}$ The effect of hyperinflation on inspiratory muscle endurance in healthy subjects is controversial. Although maximal inspiratory pressures (MIPs) are decreased at high lung volumes the ability to sustain inspiratory muscle force with repeated efforts is not compromised. ${ }^{6}$ By contrast, the endurance time for inspiratory resistive loading is significantly decreased. ${ }^{7}$

The neuromuscular consequences of acute airway narrowing in asthma, however, cannot be modelled fully by external resistive loading or hyperinflation in healthy subjects or in asthmatic subjects studied in remission. The complex neurohumoral processes and psychological factors associated with acute asthma could affect the voluntary performance of the inspiratory muscles via several mechanisms other than a simple increase in inspiratory load. Histamine induced bronchoconstriction provides a controlled method to simulate acute airway narrowing and hyperinflation, ${ }^{89}$ and it may also simulate some other features of acute asthma.

This study investigated whether histamine induced bronchoconstriction or hyperinflation (or a combination of the two) in asthmatic subjects would affect maximal strength and endurance of the inspiratory muscles in a voluntary task. Maximal static contractions were used because they allow the performance of the inspiratory muscles to be measured independently of resistance to air flow.

\section{Methods}

SUBJECTS

The endurance of the diaphragm was studied in 21 experiments performed on six asthmatic volunteers (two female and four male, aged 1934 years). One author was a subject but the other subjects were ignorant of the hypotheses being investigated. Subjects were studied on three to five separate occasions, with only one endurance test performed in any 24 hour period. All subjects had a history of episodic wheeze and chest tightness and had used asthma medications regularly or intermittently. They were not selected on the basis of severity but were required to react to his- 
tamine in an incremental challenge ${ }^{10}$ sufficiently to decrease $\mathrm{FEV}_{1}$ to $50-60 \%$ of the initial value. No subject was using oral corticosteroids and none had taken part in a respiratory muscle training programme. Informed consent was obtained and the study was approved by the institutional ethics committee.

\section{LUNG FUNCTION TESTS}

On each experimental day lung function tests and a histamine challenge or endurance test or both were all performed with the subject seated in a pressure compensated, integrated flow body plethysmograph. Flows through the airway and plethysmograph openings were measured with Hans Rudolph pneumotachometers with flow and integrated flow (volume) calibrated with a 3 litre syringe. Pressure at the airway opening was measured with a differential pressure transducer (Vacumed, 0-200 $\mathrm{cm} \mathrm{H} \mathrm{H}_{2} \mathrm{O}$ ) calibrated with a water manometer. A microcomputer acquired the flow, volume, and pressure signals from the body plethysmograph.

Thoracic gas volumes, functional residual capacity (FRC: with Boyle's law), total lung capacity (TLC) and vital capacity (VC) were measured. From the mean of at least two acceptable maximal expiratory flow-volume manoeuvres $\mathrm{FEV}_{1}$ and FVC were determined. Maximal inspiratory pressures (MIP) at different absolute lung volumes were measured in brief trial contractions ( $2-3$ seconds' duration, 5-15 optimal contractions with 20-30 second rest intervals). Subjects were coached to avoid glottic closure, which could be detected as a change in pressure with an inappropriately small change in plethysmographic volume. The absolute lung volume was calculated in the initial phase of each contraction $(-5$ to $-30 \mathrm{~cm}$ $\mathrm{H}_{2} \mathrm{O}$ ) from Boyle's law. The maximal inspiratory pressure-volume relationship ${ }^{11} 12$ was approximated for each subject with a second order polynomial.

\section{HISTAMINE CHALLENGE}

Subjects inhaled increasing concentrations of nebulised histamine acid phosphate through the mouth (via an acorn nebuliser) for one minute. $\mathrm{FEV}_{1}$ was measured one and three minutes after each challenge and the histamine concentration was increased (by doubling from $0.25 \mathrm{mg} / \mathrm{ml}$ up to $32 \mathrm{mg} / \mathrm{ml}$ ) until a $50-60 \%$ reduction in $\mathrm{FEV}_{1}$ was achieved. The $\mathrm{PC}_{20}$ for histamine (that is, the concentration required to produce a $20 \%$ reduction in $\mathrm{FEV}_{1}$ ) was estimated. ${ }^{10}$ The endurance test started as soon as the required bronchoconstriction was achieved. After the endurance test $F E V_{1}$ was measured to determine the minimal level of bronchoconstriction that had been maintained throughout the experiment. For the control experiments two one minute challenges of nebulised phosphate buffered saline were given before the endurance test. The subjects were not informed whether the solutions were saline or histamine. A separate histamine challenge (without endurance test) was administered to each subject to confirm that any induced bronchoconstriction would be sustained for the six minutes of the endurance test. The end expiratory level was determined by Boyle's law every two minutes during a period of stable, relaxed breathing.

\section{ENDURANCE TEST}

Inspiratory endurance was measured in all subjects in control experiments and during histamine induced bronchoconstriction, with each contraction performed at the subject's preferred resting end expiratory lung volume, which is higher during bronchoconstriction. ${ }^{89}$ Experiments were also conducted on five subjects under control conditions but with contractions begun at an increased lung volume determined by the experimenter (FRC $+1 / 2$ inspiratory capacity (IC)-see below). Four experiments were conducted at a similar increased lung volume but during histamine induced bronchoconstriction. In five subjects control experiments were conducted first but subsequently the order was random. The endurance test consisted of 18 maximal inspiratory efforts against a closed airway (Mueller manoeuvre) with the subject seated in the plethysmograph. ${ }^{6}$ Each contraction was sustained for 10 seconds with 10 second rest intervals $(50 \%$ duty cycle, total time six minutes). The experimenter closed the airway after the subject had inhaled to TLC and exhaled to the preferred resting end expiratory lung volume or FRC $+1 / 2$ IC. Throughout the Mueller manoeuvre the subject was continually and loudly encouraged in a standard way to maintain maximal effort. Between contractions the subject's breathing pattern was unconstrained. Initial absolute lung volume was calculated at the start of the contraction $(-5$ to

Table 1 Summary data for each subject

\begin{tabular}{|c|c|c|c|c|c|c|c|c|c|c|}
\hline \multirow[b]{2}{*}{ Subject No } & \multirow[b]{2}{*}{$\operatorname{Age}(y)$} & \multirow[b]{2}{*}{ Sex } & \multirow[b]{2}{*}{ Height $(\mathrm{cm})$} & \multicolumn{2}{|c|}{$T L C$} & \multirow[b]{2}{*}{$F R C^{\star}(i)$} & \multirow[b]{2}{*}{$V C(l)$} & \multirow[b]{2}{*}{$F E V, \dagger(l)$} & \multirow[b]{2}{*}{$F E V, \mid F V C(\%)$} & \multirow{2}{*}{$\begin{array}{l}F E V_{1}(H) \dagger \\
(\% \text { control })\end{array}$} \\
\hline & & & & (l) & $(\% \text { pred })^{13}$ & & & & & \\
\hline $\begin{array}{l}1 \\
2 \\
3 \\
4 \\
5 \\
6\end{array}$ & $\begin{array}{l}19 \\
36 \\
24 \\
34 \\
22 \\
22\end{array}$ & $\begin{array}{l}\mathbf{F} \\
\mathbf{M} \\
\mathbf{M} \\
\mathbf{M} \\
\mathbf{F} \\
\mathbf{M}\end{array}$ & $\begin{array}{l}162 \\
175 \\
178 \\
167 \\
173 \\
172\end{array}$ & $\begin{array}{l}6.0 \\
9.8 \\
7.6 \\
6.2 \\
6.5 \\
7.5\end{array}$ & $\begin{array}{r}122 \\
142 \\
107 \\
98 \\
116 \\
112\end{array}$ & $\begin{array}{l}2 \cdot 6 \\
5 \cdot 8 \\
3 \cdot 6 \\
2 \cdot 6 \\
3 \cdot 4 \\
3 \cdot 2\end{array}$ & $\begin{array}{l}4 \cdot 8 \\
5 \cdot 2 \\
6 \cdot 2 \\
4 \cdot 8 \\
4 \cdot 7 \\
5 \cdot 4\end{array}$ & $\begin{array}{l}4 \cdot 2 \\
2 \cdot 7 \\
4 \cdot 4 \\
3 \cdot 7 \\
3.5 \\
3.9\end{array}$ & $\begin{array}{l}88 \\
40 \\
71 \\
77 \\
74 \\
71\end{array}$ & $\begin{array}{l}67 \\
52 \\
60 \\
60 \\
53 \\
39\end{array}$ \\
\hline $\begin{array}{l}\text { Mean } \\
\text { SD }\end{array}$ & $\begin{array}{r}26 \\
7\end{array}$ & & $\begin{array}{r}171 \\
6\end{array}$ & $\begin{array}{l}7 \cdot 3 \\
1 \cdot 4\end{array}$ & $\begin{array}{r}116 \\
15\end{array}$ & $\begin{array}{l}3.5 \\
1.2\end{array}$ & $\begin{array}{l}5 \cdot 2 \\
0.6\end{array}$ & $\begin{array}{l}3.7 \\
0.6\end{array}$ & $\begin{array}{l}70 \\
16\end{array}$ & $\begin{array}{l}55 \\
11\end{array}$ \\
\hline
\end{tabular}

^Functional residual capacity (FRC) is the average initial absolute lung volume for the control experiments.

†Forced expiratory volume in one second $\left(\mathrm{FEV}_{1}\right)$ control values are shown and also $\mathrm{FEV}$, after histamine induced bronchoconstriction $(\mathrm{H})$, expressed as $\%$ control.

TLC-total lung capacity; VC_-vital capacity. 
Table 2 Mean (SD) values for maximal inspiratory pressure (MIP), average initial absolute lung volume (from all contractions), and endurance for each type of experiment

\begin{tabular}{|c|c|c|c|c|c|c|}
\hline & \multirow[b]{3}{*}{ Subjects $(n)$} & \multirow{3}{*}{$\begin{array}{l}\text { Initial volume } \\
\text { (lor } \% \text { control) }\end{array}$} & \multirow{2}{*}{\multicolumn{2}{|c|}{$M I P$}} & \multicolumn{2}{|l|}{ Endurance $\dagger$} \\
\hline & & & & & \multirow{2}{*}{$\begin{array}{l}\text { Peak } \\
\text { (\% expected) }\end{array}$} & \multirow{2}{*}{$\begin{array}{l}\text { Average } \\
\text { (\% expected })\end{array}$} \\
\hline & & & $\left(\mathrm{cm} \mathrm{H}_{2} \mathrm{O}\right)$ & $(\% \text { expected })^{\star}$ & & \\
\hline Control & 6 & $3 \cdot 5(1 \cdot 2)$ & $-114(22)$ & $97(7)$ & $88(6)$ & $70(10)$ \\
\hline Histamine & 6 & $118 \%(5 \%)$ & $-100(20)$ & $99(8)$ & $91(5)$ & $72(8)$ \\
\hline High lung volume & 5 & $140 \%(12 \%)$ & $-83(16)$ & $103(7)$ & $83(9)$ & $60(10)$ \\
\hline Histamine - high lung volume & 4 & $140 \%(15 \%)$ & $-81(25)$ & $95(12)$ & $85(5)$ & $69(4)$ \\
\hline
\end{tabular}

^Percentage of the pressure expected from the maximal inspiratory pressure-volume relationships (see under "Methods").

†The larger peak and average pressure (\% expected) of the last two contractions in each test.

$-30 \mathrm{~cm} \mathrm{H}_{2} \mathrm{O}$ ) and stored in a microcomputer. Airway pressure was acquired at $85 \mathrm{~Hz}$ and stored, and peak and average pressures were calculated.

ANALYSIS

Because of inevitable variations in initial absolute lung volume during each sequence of 18 contractions, and intentional variations in initial volume between the four experiments, the maximal inspiratory pressure-volume relationship determined for each subject was used to normalise the values of airway pressure. A graphical method for this correction has been reported previously. ${ }^{6}$ The pressure "expected" for each inspiratory effort in the endurance test was calculated from the initial volume and the second order polynomial fitted to the pressurevolume data (see above). The peak and average pressures of each contraction were then expressed as percentages of the derived maximal pressure expected at that lung volume.

One estimate of endurance for each experiment was calculated as the percentage of expected pressure achieved in the better of the last two contractions of the series. Analyses of variance and covariance (SPSS) were applied to the peak and average pressures $(\%$ expected pressure) from each of the 18 contractions with subject and type of experiment (control, histamine, high lung volume, and histamine at high lung volume) as main effects and with

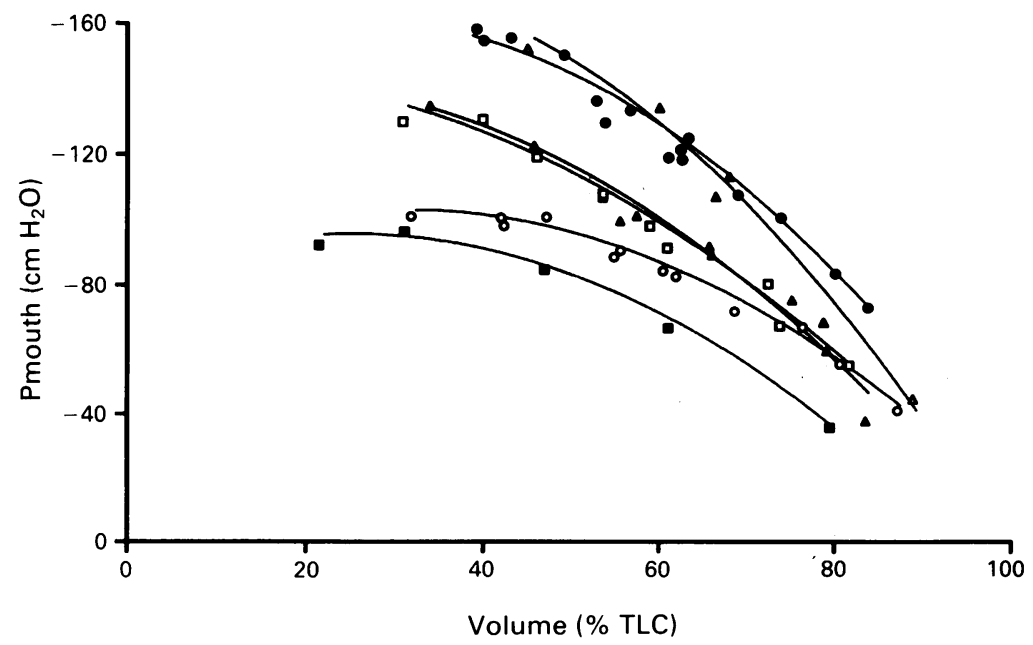

Figure 1 Relation between maximal inspiratory pressure (Pmouth) and initial absolute lung volume (\% observed total lung capacity (TLC) for the six subjects. A second order polynomial curve has been fitted to the data for each subject. contraction number as a covariate. Unless it is stated otherwise, values are reported as means with standard deviations in parentheses.

\section{Results}

LUNG FUNCTION AND BRONCHOCONSTRICTION

Summary data for each subject (age, sex, height, and lung function) are given in table 1 . After histamine challenge and immediately before the endurance test, mean $\mathrm{FEV}_{1}$ decreased to $55 \%(11 \%)$ of the prechallenge value. Immediately after the endurance test mean $\mathrm{FEV}_{1}$ was $72 \%(11 \%)$ of the prechallenge value. During bronchoconstriction the average initial volume for the endurance tests was increased significantly, ranging from $112 \%$ to $123 \%$ of the control volume ( $p<0.01$ : see table 2). The mean $P_{20}$ for all subjects was $6 \cdot 7(8 \cdot 7)$ $\mathrm{mg}$, ranging from 0.5 to $23 \mathrm{mg}$.

When recovery from histamine induced bronchoconstriction was investigated in each subject without an endurance test, mean $\mathrm{FEV}_{1}$ decreased to $56 \%$ (15\%) and recovered to $68 \%$ $(14 \%)$ of the prechallenge $\mathrm{FEV}_{1}$ within 10 minutes. Mean end expiratory lung volume (measured in five subjects) initially increased to $124 \%(13 \%)$ of the prechallenge value and then decreased to $115 \%(10 \%)$ within 10 minutes. End expiratory lung volume declined linearly as $F E V_{1}$ increased ( $p<0.05$, linear regression). All endurance tests (duration six minutes) were completed within 10 minutes of the last dose of histamine. Thus the endurance test had minimal influence on the duration of bronchoconstriction or the increase in end expiratory lung volume.

\section{INSPIRATORY MUSCLE PERFORMANCE}

Figure 1 shows the maximal inspiratory pressure-volume curves obtained from the six subjects under control conditions. All contractions during the endurance test were within the range of lung volumes used to determine the maximal pressure-volume curves (see also tables 1 and 2).

Representative traces of mouth pressure for subject 3 are shown in figure 2 for the control and histamine endurance tests. Peak pressure was reached in the first 3 seconds of each contraction and pressure then declined progressively with some oscillations. In figure 3 the peak mouth pressures for the 72 contractions performed by subject 3 are plotted as a function of initial absolute lung volume (\% observed TLC), and the maximal inspiratory 


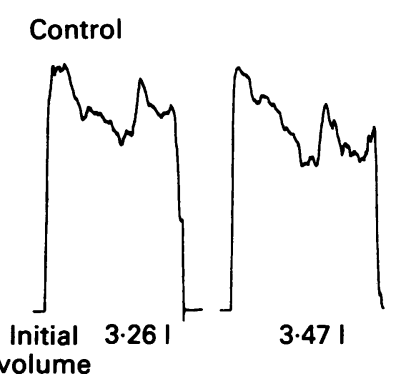

Histamine

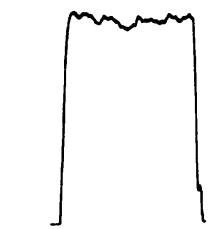

Initial 4.68 volume

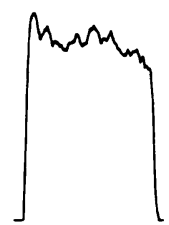

4.541

Early

Figure 2 Maximal static inspiratory pressure (Pmouth) (negative) for a representative subject during contractions early and late in a control series of 18 contractions (above) and after histamine induced bronchoconstriction (below). Contractions are separated by intervals of 10 seconds.

pressure-volume curve obtained independently for that subject is superimposed. The initial volumes differ between experiments but the variation in peak mouth pressure is predicted by the shape of the pressure-volume curve. Data in figure 3 suggest that the relation between peak inspiratory pressure and lung volume does not change as peak pressure decreases owing to fatigue in each experiment. Group data for each contraction are plotted in figure 4, which compares control and histamine experiments (six subjects), control and control- . high lung volume experiments (five subjects), and control-high lung volume and histaminehigh lung volume experiments (four subjects). The peak and average pressures (\% expected) show a progressive decline with time for all four conditions. Initial volume (fig 4, right) did not change significantly between contractions (analysis of variance).

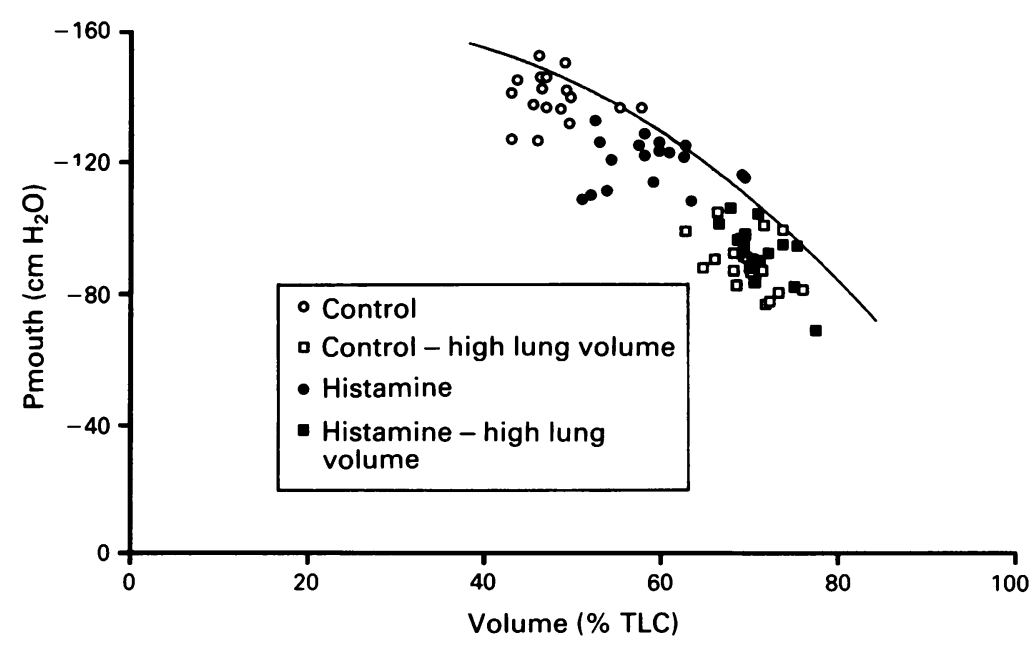

Figure 3 Data from a representative subject. Peak pressures obtained in the 18 contractions from the four endurance sequences plotted against the initial absolute lung volume (LV;\% observed total lung capacity (TLC)) at which the contractions started. The maximal static inspiratory pressure (Pmouth)-volume relationship for that subject is superimposed.
During bronchoconstriction the average initial volume for the 18 contractions was significantly increased (see above). For studies at high lung volume, however, there was no significant difference in mean initial volume with and without histamine (table 2). In the control experiments the maximal inspiratory pressure (MIP) ranged from -92 to $-150 \mathrm{~cm}$ $\mathrm{H}_{2} \mathrm{O}$ and $\mathrm{MIP}$ was reduced significantly at high lung volumes (table 2). When, however, MIP was normalised to the pressure expected at that lung volume (calculated from the maximal inspiratory pressure-volume curve-see above) it did not differ between the four types of experiment. The mean MIP for all experiments was $99 \%(8 \%)$ of the expected pressure (21 experiments, range 84-116\% expected).

When the peak and average pressures (\% expected) in the better of the final two contractions of each experiment were used to quantify endurance, no significant differences were found between any of the types of experiments (table 2). When analyses of variance and covariance were used to compare the peak and average pressure (\% expected) for all contractions between the four types of experiments there was no significant effect on inspiratory muscle performance due to hyperinflation or histamine induced bronchoconstriction.

\section{Discussion}

This study shows that hyperinflation and histamine induced bronchoconstriction in asthmatic subjects do not impair inspiratory muscle strength or endurance in a six minute test requiring repeated maximal efforts, and confirm the previous finding that the inspiratory muscles are resistant to fatigue. ${ }^{45}$ Fatigue is defined here as any reduction in the force (or velocity) generating capacity of a muscle. Using the same protocol with non-asthmatic subjects, McKenzie and Gandevia ${ }^{14}$ found a similar decline in mouth pressure (to $87 \%$ of the initial maximal pressure), but for the elbow flexors to decline to a similar value the duty cycle had to be decreased 10 fold, from $50 \%$ to $5 \%$ (that is, the rest interval between contractions was increased from 10 to 200 seconds). In a previous study ${ }^{4}$ asthmatic subjects showed greater endurance of inspiratory and expiratory muscles than matched control subjects but similar endurance of the elbow flexors. Their asthma, however, was poorly controlled, and they were selected on the basis of daily symptomatic wheeze of at least 20 minutes' duration to determine whether intermittent airflow obstruction was a training stimulus to the inspiratory muscles. The patients in the present study were unselected apart from the requirement to react to histamine sufficiently to make the $\mathrm{FEV}_{1}$ fall to $50-60 \%$ of the initial value. The finding that hyperinflation does not necessarily impair inspiratory muscle endurance is consistent with previous results in non-asthmatic subjects. ${ }^{6}$

During a histamine challenge some subjects complain of headache, flushing, and coughing, which might impair voluntary performance. 
Figure 4 Pooled data comparing the different experimental conditions: peak pressure (Pmouth) as $\%$ expected for each contraction (left) and initial lung volume (right). Data from six subjects are shown for the control and histamine comparison (top), from five subjects for the control and control-high lung volume comparison (middle), and from four subjects for the control high lung volume and histamine-high lung volume comparison (bottom). Bars indicate standard errors. Analyses of variance and covariance showed no significant differences for any of the comparisons of maximal pressures or for lung volume in the high lung volume comparison (bottom right). For clarity the values for the average pressure sustained for 10 seconds during each contraction are not shown. As with peak pressure, no significant differences were found.
Peak mouth pressure
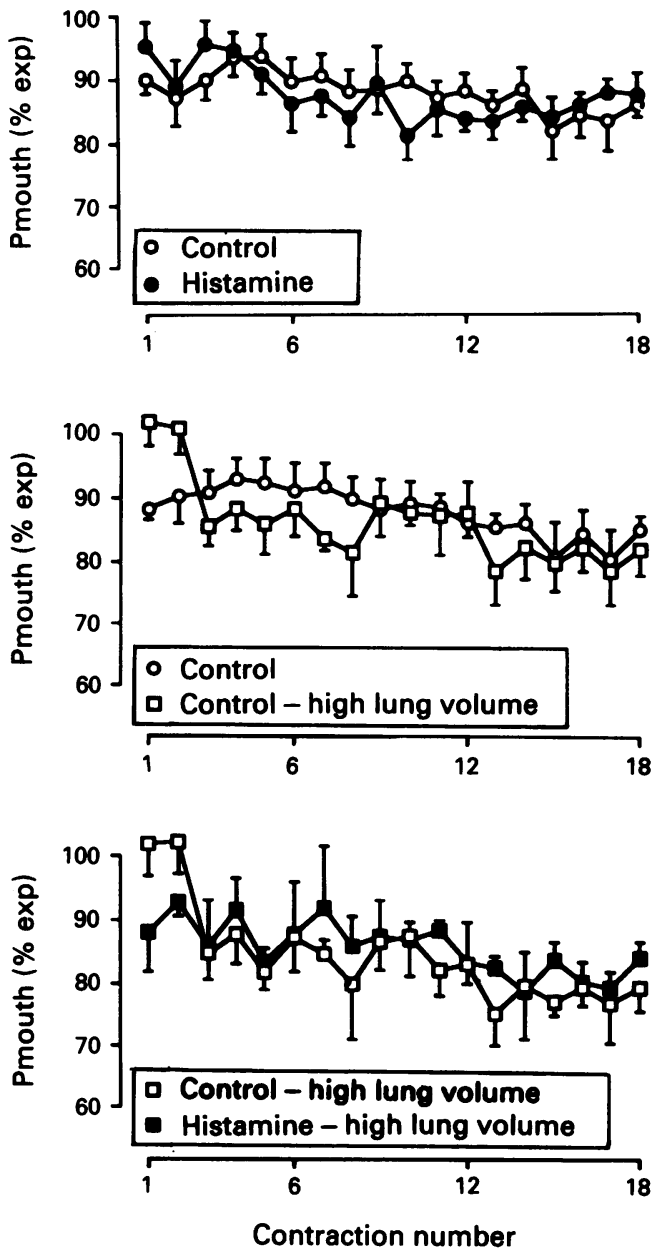

The airway narrowing and hyperinflation that accompany bronchoconstriction increase the resistive and elastic loads on breathing between the maximal static contractions, and this may accelerate fatigue of the inspiratory muscles. ${ }^{7}$ Histamine also stimulates many airway and interstitial receptors, some of which may have inhibitory reflex effects on the inspiratory muscles. ${ }^{15}$ Despite these possible influences on voluntary performance, histamine induced bronchoconstriction appeared to have no effect on the ability to develop maximal inspiratory pressures or on endurance.

In previous studies we have shown in healthy subjects that the diaphragm can be fully activated by voluntary drive during maximal static inspiratory efforts ${ }^{16}$ while the inspiratory intercostal and accessory muscles are submaximally activated. ${ }^{17}$ Thus the diaphragm is the limiting muscle in this endurance test, so that the decline in MIP principally reflects diaphragmatic fatigue..$^{18}$ If the ability to activate the diaphragm voluntarily during maximal efforts varies with lung volume, an effect of histamine induced bronchoconstriction on diaphragm performance may have been masked. Obviously submaximal static efforts can be sustained longer than maximal efforts. Thus if the subjects were less able to activate the diaphragm voluntarily at high lung volumes any increase in fatigability due to hyperinfla-
Initial lung volume
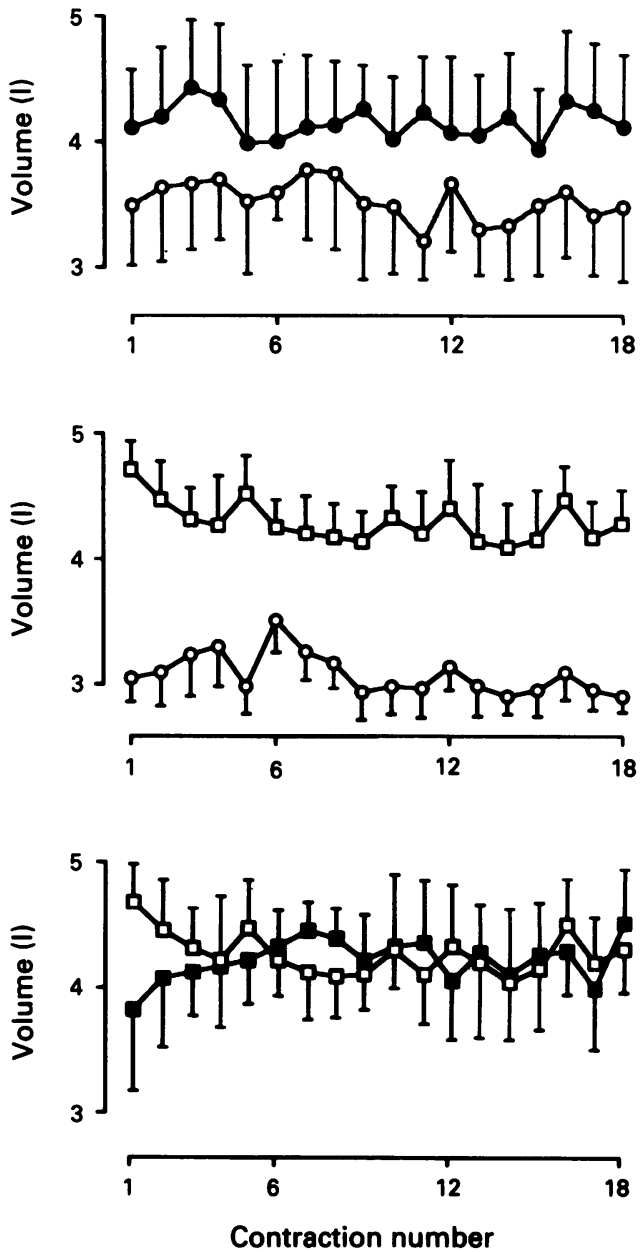

tion may have been counterbalanced by a reduced rate of development of fatigue because contractions were submaximal. When tests with and without histamine were performed at the same high lung volume, however, there was no effect of histamine on inspiratory muscle performance. Limb muscles can be fully activated at short muscle lengths, ${ }^{19}$ though this has not been studied formally for the diaphragm with phrenic nerve stimulation.

The relative increase in end expiratory lung volume during histamine induced bronchoconstriction ( $118 \%$ of the control volume) was smaller than that reported in a previous study, ${ }^{8}$ which showed a $49 \%$ increase for a $50 \%$ reduction of $\mathrm{FEV}_{1}$. The plethysmographic technique may, however, overestimate absolute lung volume during bronchoconstriction, particularly when the panting frequency is greater than $1 \mathrm{~Hz}^{2021}$ Indirect evidence suggests that the increase in end expiratory lung volume documented here was measured accurately. Using oesophageal pressure instead of mouth pressure to estimate absolute lung volume, Stanescu et $a l^{20}$ found that end expiratory lung volume increased to $121 \%$ of the control volume with acetylcholine induced bronchoconstriction $\left(\mathrm{FEV}_{1} 59 \%\right.$ control), which is similar to our results. The present results also show no shift in the maximal static inspiratory pressure-lung volume relationship 
with histamine induced bronchoconstriction, which would be expected with an increase in volume due to measurement artefact. ${ }^{22}$

The present results indicate that neither hyperinflation nor histamine induced bronchoconstriction produces any specific impairment of diaphragmatic performance. Further studies will be required to determine whether naturally occurring acute exacerbations of severe narrowing of the airways in asthma produce any impairment in respiratory muscle contractile properties or in the ability to activate the diaphragm fully.

This study was supported by the National Health and Medica Research Council of Australia and the Asthma Foundation of New South Wales. We are grateful to Professor HJH Colebatch for comments on the manuscript.

1 Roussos CS, Macklem PT. Diaphragmatic fatigue in man. $J$ Appl Physiol 1977;43:189-97.

2 Roussos C, Macklem PT. The respiratory muscles. $N$ Engl $J$ Med 1982;307:786-97.

3 Leith DE, Bradley $M$. Ventilatory muscle strength and endurance training. J Appl Physiol 1976;41:508-16.

4 McKenzie DK, Gandevia SC. Strength and endurance of inspiratory, expiratory and limb muscles in asthma. $\mathrm{Am}$ inspiratory, expiratory and limb mus

5 Newell SZ, McKenzie DK, Gandevia SC. Inspiratory and skeletal muscle strength and endurance and diaphragmatic activation in patients with chronic airflow limitation. Thorax 1989;44:903-12.

6 McKenzie DK, Gandevia SC. Influence of muscle length on human inspiratory and limb muscle endurance. Respir Physiol 1987;67:171-82.

7 Roussos C, Fixley M, Gross D, Macklem PT. Fatigue of inspiratory muscles and their synergic behaviour. $J A p p l$ Physiol 1979;46:879-904.
8 Martin J, Powell E, Shore S, Emrich J, Engel LA. The role of respiratory muscles in the hyperinflation of bronchial asthma. Am Rev Respir Dis 1980;121:441-7.

9 Muller N, Bryan AC, Zamel N. Tonic inspiratory muscle activity as a cause of hyperinflation in histamine-induced activity as a cause of hyperinflation in hist
asthma. $J$ Appl Physiol 1980;49:869-74.

10 Cockcroft DW, Killian DN, Adrian Mellon JJ, Hargreave FE. Protective effect of drugs on histamine-induced asthma. Thorax 1977;32:429-37.

11 Rohrer F. Der Zusammenhang der Atemkraefte und ihre Abhaengigkeit vom Dehnungszustand der Atmungsorgane. Pflügers Arch ges Physiol 1916;165:419-44.

$12 \mathrm{Rahn} \mathrm{H}$, Otis AB, Chadwick LE, Fenn WO. The pressurevolume diagram of the thorax and lung. Am J Physiol 1946;146:161-78.

13 Quanjer $\mathrm{PhE}$, ed. Standardized lung function testing. Report of working party on the standardization of lung function tests. Bull Eur Physiopathol Respir 1983;19(suppl 15):1-95

14 McKenzie DK, Gandevia SC. Recovery from fatigue of human diaphragm and limb muscles. Respir Physiol 991;84:49-60.

15 Coleridge HM, Coleridge JCG, Jordan D. Integration of ventilatory and cardiovascular control systems. In: Crystal RG, West JB, eds. The lung: scientific foundations. New York: Raven, 1991: 1405-18.

16 Gandevia SC, McKenzie, DK. Activation of the human diaphragm during maximal static efforts. $J$ Physiol ( Lond ) 1985;367:45-56

17 Gandevia SC, McKenzie, DK, Plassman, BL. Activation of human respiratory muscles during different voluntary manoeuvres. J Physiol (Lond) 1990;428:387-403.

18 Gandevia SC, McKenzie, DK. Human diaphragmatic endurance during different maximal respiratory efforts. $J$ endurance during different maximal

19 Gandevia SC, McKenzie DK. Activation of human muscles at short muscle lengths during maximal static efforts. $J$ Physiol (Lond) 1988;407:599-613.

20 Stanescu DC, Rodenstein D, Cauberghs M, Van de Woestijne KP. Failure of body plethysmography in bronchia asthma. J Appl Physiol 1982;52:939-48.

21 Shore S, Milic-Emili J, Martin JG. Reassessment of body plethysmographic technique for the measurement of thoracic gas volume in asthmatics. Am Rev Respir Dis 1982;126:515-20.

22 Peress L, Sybrecht G, Macklem PT. The mechanism of increase in total lung capacity during acute asthma. $\mathrm{Am} \mathrm{J}$ Med 1976;61:165-9. 